\title{
COMPARATIVE TOXICOLOGICAL ASSESSMENT OF A WATER-SOLUBLE AZOLE ADMINISTERED BOTH ORALLY AND BY INTRAVENOUS CONTINUOUS INFUSION IN CYNOMOLGUS MONKEYS
}

\author{
Kazuko KOBAYASHI and Ikuo HORII \\ Department of Preclinical Science, Nippon Roche Research Center, \\ 200 Kajiwara, Kamakura, Kanagawa 247-8530, Japan
}

(Received November 7, 2001; Accepted January 30, 2002)

\begin{abstract}
The water-soluble azole, 4-[1-[(3-methylaminoacetoxymethyl-pyridin-2-yl)-methyl-carbamoyloxy]-ethyl]-1-[(2R,3R)-3-[4-(4-cyano-phenyl)-thiazol-2-yl]-2-(2,5-difluoro-phenyl)-2-hydroxy-butyl]$1 \mathrm{H}-[1,2,4]$ triazol-4-ium chloride hydrochloride (hereinafter referred to as WSA), is a new water-soluble triazole anti-fungal compound. WSA is rapidly converted into its active metabolite after administration by either the intravenous or oral route. The clinical effects of WSA are expected to be consistent whether it is administered by injection (intravenous) or orally.

To evaluate and compare the toxicities of WSA via oral and intravenous administration, repeated toxicity studies of WSA were conducted in cynomolgus monkeys (oral dosage levels: $0,10,30$ and $90 \mathrm{mg} /$ $\mathrm{kg} /$ day over a 4-week period; intravenous infusion dosage levels: $0,10,30$ and $60 \mathrm{mg} / \mathrm{kg} /$ day over a 2week period). In addition, a 2 -week oral toxicity study of the active metabolite of WSA was conducted with similar dosages $(0,10,30$ and $90 \mathrm{mg} / \mathrm{kg} /$ day $)$.

From the results obtained from the evaluation, hepatotoxicity (liver) and endocrinological toxicity (adrenals) were the major toxicities, a finding which is comparable to other previously tested azole compounds.

In the 4-week oral toxicity study, the lethal dose of WSA was determined to be $90 \mathrm{mg} / \mathrm{kg}$. However, no animal mortality was observed during the 2-week intravenous continuous infusion study.

The toxicokinetics (TK) profile of WSA at 10 and $30 \mathrm{mg} / \mathrm{kg}$ dosages illustrated a rapid, dose-dependent conversion of WSA to its active metabolite, and the plasma levels of $\mathrm{C}_{\max }$ and AUC were well correlated to their toxicities. However, at high dosages $(60$ and $90 \mathrm{mg} / \mathrm{kg}$ ), WSA demonstrated high exposure beyond the dose-proportional manner. Overall, the results obtained indicate that maintaining an effective concentration and a non-toxic dosage level would be manageable by utilizing an initial intravenous continuous infusion followed by oral administration.
\end{abstract}

KEY WORDS: Antifungal, Triazole, Water-soluble azole, Intravenous infusion

\section{INTRODUCTION}

Recently, the number of patients who are suffering from deep-seated mycosis is increasing, and the necessity for development of systemic antifungal therapy is increasing. However, current drugs for the treatment of deep-seated mycosis are usually administered via an oral route, because of their high lipophilicity (low solubility). These drugs also have a narrow antifungal spectrum with several toxicities in the liver and endocrinological organs (Van Cauteren et al., 1989).
Furthermore, drug-resistant strains of fungus have been encountered after treatment with the existing azole antifungal drugs (Yamaguchi, 2000; Niki et al., 1999). To improve these critical issues, a water-soluble azole drug has been sought for the treatment of severe and deep seated mycoses, especially for hospitalized patients, which can be applicable orally and via intravenous administration.

WSA is a new water-soluble azole derivative with a broad antifungal spectrum of efficacy, and is suitable for both injectable and oral treatment. WSA is rapidly 
converted into its active form by esterase, and the active compound is highly inhibitory against ergosterol synthesis. Its active compound was identified as having a broad antifungal spectrum and a good safety profile including a low drug-drug interaction. However, water solubility was too low for intravenous injection, so a prodrug (WSA) was designed for improving water solubility.

This paper examines the toxicological profile of WSA via oral administration and intravenous continuous infusion in monkeys, as well as its safety assessment for this compound.

\section{MATERIALS AND METHODS}

The study described in this paper was carried out in accordance with the guidelines of the Nippon Roche Research Center Committee for Experimental Animals (based on the Guide for the Care and Use of Laboratory Animals, NIH OACU) on the use of laboratory animals in research.

\section{Test article}

The test article, a water-soluble azole (WSA), is a white powder, and has the chemical name of 4-[1-[(3methylaminoacetoxymethyl-pyridin-2-yl)-methyl-carbamoyloxy]-ethyl]-1-[(2R,3R)-3-[4-(4-cyano-phenyl)thiazol-2-yl]-2-(2,5-difluoro-phenyl)-2-hydroxybutyl]-1H-[1,2,4]triazol-4-ium chloride hydrochloride.

The active metabolite is also a white powder and has the chemical name of (1R,2R)-4-[2-[2-(2,5-difluoro-phenyl)-2-hydroxy-1-methyl-3-[1,2,4]triazol-1-ylpropyl]-thiazol-4-yl]-benzonitrile. The WSA and the active metabolite utilized in this study were produced at Nippon Roche Research Center (NRRC). The chem- ical structures of WSA and the active metabolite are shown in Fig. 1.

\section{Animals and housing conditions}

Healthy cynomolgus monkeys (Macaca fascicularis, purpose-bred; 3 to 6 years old), purchased from SNBL Service (Shin Nippon Biomedical Laboratories, Ltd., Kagoshima, Japan) were used in this study following an appropriate quarantine and acclimation period.

The body weights of these monkeys at the initiation of the treatment period range from 3.7 to $5.0 \mathrm{~kg}$ for the males and from 2.6 to $3.8 \mathrm{~kg}$ for the females. The animals were housed in an air-conditioned room (room temperature $25 \pm 2^{\circ} \mathrm{C}$; relative humidity $55 \pm 10 \%$ ) and kept individually in metal cages, with 12-hr periods of light and dark. They were provided approximately 100 g/day of food to eat (Primate diet \#5048, PMI Feeds Inc., USA) and tap water (ad libitum).

For the infusion study, the catheter was implanted into the vena cava via the femoral vein under anesthetization, approximately two weeks prior to the initiation of the treatment period (Mendenball, 2000; Walker, 2000).

\section{Study types, dosages and drug preparation/admin- istration methods}

Study types for the comparative safety assessment of oral and infusion administration consisted of a 4-week oral administration of WSA with 2-week interim tests, a 2-week infusion administration of WSA, and a 2-week oral administration of the active metabolite.

The dosages, drug preparation and drug administration methods employed in this study are summa-<smiles>C[NH2+]CNCC(=O)OC(C)[n+]1cnn(C[C@@](O)(c2cc(F)ccc2F)C(C)[C@H](C)c2nc(-c3ccc(C#N)cc3)cs2)c1</smiles>

WSA

Molecular Weight: 789.7

Water solubility: > $1000 \mathrm{mg} / \mathrm{ml}$ Purity: $98.35 \%$<smiles>CC(c1nc(-c2ccc(C#N)cc2)cs1)[C@](O)(Cn1cncn1)c1cc(F)ccc1F</smiles>

Active metabolite of WSA

Molecular weight: 437.5

Purity: $99.71 \%$

Fig. 1. Chemical structure of WSA and the active metabolite of WSA. 
Comparative toxicological assessment of WSA in cynomolgus monkeys.

rized in Table 1.

\section{Observations and examination designs 1. General conditions}

All of the monkeys were observed daily during both the treatment and recovery periods, and mortality and clinical signs were recorded.

The body weight measurements for each monkey were carried out and recorded, once a week for the 4week study and twice a week for the 2-week studies. Daily food consumption was also monitored and recorded for each monkey.

\section{Clinical testing}

1) Hematological examinations

Blood samples were collected from the femoral or limb veins of each monkey. EDTA-2K was used as the anticoagulant. Blood samples were obtained before the initial WSA or active metabolite treatment (Day 0) and on the final drug administration day (Day 13 for the 2-week studies, Day 27 for the 4-week study), at the midpoint of the treatment period for the 4-week study (Day 13) and at the end of the recovery period.

The following values were determined or calculated from assay data measured by a multipurpose automatic cell counter (Technicon auto-analyzer $\mathrm{H}^{*} 1$, Technicon Co., Ltd., USA): red blood cell count, white blood cell count, hemoglobin concentration, hematocrit, platelet count, mean corpuscular volume, mean corpuscular hemoglobin and mean corpuscular hemoglobin concentration. Hemogram (differential cell count: neutrophil, eosinophil, basophil, monocyte and lymphocyte) was indicated as a ratio or percentage. The reticulocytes were counted by the Brecher method using Sysmex F-300 (TOA Medical Electronics, Japan).

\section{2) Blood chemical analyses}

Blood samples for serum analyses were collected utilizing the same procedure as was previously described above for hematology, excluding the anticoagulant. The following clinical assays were performed on an autoanalyzer, the H7150 (Hitachi Ltd., Tokyo, Japan): GOT (glutamic oxaloacetic transaminase), GPT (glutamic pyruvic transaminase), ALP (alkaline phosphatase), total protein, albumin, glucose, TG (triglyceride), T-CHO (total cholesterol), BUN (blood urea nitrogen), creatinine, total bilirubin, calcium, inorganic phosphorus, sodium, potassium and chloride, and an A/G (albumin/globulin ratio) was calculated.

\section{Pathological examination}

\section{1) Necropsy findings}

The monkeys that expired during the treatment period were necropsied as soon as possible after the confirmation of their death. All surviving monkeys were euthanized either at the end of the treatment period or at the end of the recovery period. These mon-

Table 1. Study types, dosages, drug preparation and drug administration methods.

\begin{tabular}{lccc}
\hline \multicolumn{1}{c}{ Test article } & WSA & WSA & Active metabolite of WSA \\
\hline Administration route & p.o. & i.v. continuous infusion & p.o. \\
Administration period & 4 weeks & 2 weeks & 2 weeks \\
Recovery period & 4 weeks & 4 weeks & $-10,30,90 \mathrm{mg} / \mathrm{kg}$ \\
\hline Dose levels & $0,10,30,90 \mathrm{mg} / \mathrm{kg}$ & $0,10,30,60 \mathrm{mg} / \mathrm{kg}$ & $0.5 \% \mathrm{CMC}-\mathrm{Na}$ solution \\
Carrier & water $(\mathrm{pH} 3.5 \pm 0.1)$ & saline $(\mathrm{pH} 3.5 \pm 0.1)$ & $5,15,45 \mathrm{mg} / \mathrm{ml}$ \\
Concentration & $5,15,45 \mathrm{mg} / \mathrm{ml}$ & $0.8,2.4,4.8 \mathrm{mg} / \mathrm{ml}$ & $2 \mathrm{ml} / \mathrm{kg}$ \\
Dosage volume & $2 \mathrm{ml} / \mathrm{kg}$ & $6.25 \mathrm{ml} / \mathrm{kg} / \mathrm{hr}, 2 \mathrm{hr} / \mathrm{day}$ & - \\
Dosage speed & - & $12.5 \mathrm{ml} / \mathrm{kg} / 2 \mathrm{hr} / \mathrm{day}$ & naso-gastric tube \\
Administration method & naso-gastric tube & syringe pump: KDS220 & $1 / \mathrm{sex} / \mathrm{dose}$ \\
Number of animals used & $4 / \mathrm{sex} / \mathrm{dose}$ & $4 / \mathrm{sex} / \mathrm{dose}$ &
\end{tabular}

\# Three animals/sex/dose were euthanized at the end of the treatment period and one animal/sex/dose was euthanized at the end of the recovery period. 


\section{K. KOBAYASHI et al.}

keys were terminated by exsanguination using the axillary artery/vein under anesthesia and their necropsy findings were recorded.

\section{2) Organ weights (absolute and relative)}

The following organs were weighed and the relative organ weights (organ weight per $\mathrm{kg}$ of body weight) were calculated based on the final body weight measurement: brain (including cerebellum and brain stem), pituitary, thyroids (including parathyroid), salivary glands (submandibular and sublingual glands), thymus, lung (including trachea and bronchus), heart, liver, pancreas, spleen, adrenals, kidneys, testes, epididymides, seminal vesicles, prostate, ovaries, and uterus (including vagina).

\section{3) Histopathological examination}

Histopathological specimens for all of the monkeys were sampled and prepared from the following organs and tissues: brain (cerebrum, cerebellum and medulla oblongata), pituitary, thyroids, parathyroid, salivary glands (submandibular and sublingual glands), thymus, lung, bronchus, trachea, heart, liver, gallbladder, spleen, adrenals, kidneys, testes, epididymides, seminal vesicles, prostate, ovaries, uterus, vagina, pancreas, stomach, duodenum, jejunum, ileum, colon, rectum, spinal cord, aorta, tongue, esophagus, skin, eyeballs, mammary gland, skeletal muscle, urinary bladder, mesenteric lymph node, bone marrow (femur), sternum, sciatic nerve, lachrymal gland, injection site (tissue around the vein where the tip of the catheter was located) and any other gross lesions that were uncovered.

The organs above, excluding the eyeballs, testes and epididymides, were fixed with $15 \%$ buffered formalin ( $\mathrm{pH}$ 6.8), embedded in paraffin, sectioned, stained with hematoxylin-eosin and then closely examined using a light microscope. The eyeballs were fixed with a combined glutaraldehyde/formalin fixative and then refixed in $15 \%$ buffered formalin ( $\mathrm{pH} \mathrm{6.8).} \mathrm{The}$ testes and epididymides were fixed with Bouin's solution. The eyeballs, testes and epididymides were then processed the same as the other tissues described above and examined histopathologically.

\section{Toxicokinetics}

Blood samples (approx. $0.5 \mathrm{ml} /$ point) were collected from the limb vein with heparin used as the anticoagulant on the first treatment day, on the midpoint day of the treatment period, and on the final treatment day.

For the 4-week oral administration study of WSA, samples were obtained prior to treatment and 1, 2, 4, 7 and $24 \mathrm{hr}$ after administration on Days 0 and 27. On Day 13, samples were obtained prior to treatment and $4 \mathrm{hr}$ following administration.

For the 2-week intravenous continuous infusion study of WSA, samples were obtained prior to treatment, 1, 2, 4, 7 and $24 \mathrm{hr}$ after the start of 2-hr continuous infusion on Days 0 and 13. On Day 7, samples were obtained prior to treatment and $2 \mathrm{hr}$ after the start of 2-hr continuous infusion.

For the 2-week oral administration of the active metabolite study, samples were obtained prior to treatment and 1, 2, 4, 7 and $24 \mathrm{hr}$ after administration on Days 0,7 and 13 .

Immediately after the collection of each specimen, citric acid and paraoxon were added to facilitate the stabilization of the WSA. Samples were centrifuged and plasma level profiles of WSA, its active metabolite and its pro-moiety were measured using LC/MS/MS (PE SCIEX API, Applied Biosystems, CA, USA).

\section{Statistical analysis}

The data collected were expressed as the mean \pm S.D.

Statistical analysis was performed using Pitman test (Lehmann, 1975) for the hematology and blood chemistry values, as well as the organ weights. The $p$ values less than $0.05(\mathrm{p}<0.05)$ were regarded as being statistically significant compared to the control group.

\section{RESULTS}

\section{General conditions}

At the $90 \mathrm{mg} / \mathrm{kg}$ level of WSA via oral administration, two female monkeys expired on Days 16 and 25 , respectively, both exhibiting severe emaciation. Severe to moderate emaciation, with a remarkable reduction of both body weight and food consumption was observed in the $90 \mathrm{mg} / \mathrm{kg}$ WSA and the active metabolite treatment groups. Vomiting, soft stool or diarrhea, and a decrease in spontaneous motor activity were occasionally observed slightly in the $30 \mathrm{mg} / \mathrm{kg}$ group receiving oral administration of WSA, while these signs were described as moderate in the 60 and $90 \mathrm{mg} / \mathrm{kg}$ groups receiving oral or intravenous administration of WSA and the active metabolite. 
Comparative toxicological assessment of WSA in cynomolgus monkeys.

\section{Major toxicity effects elicited by WSA}

The primary or most significant toxicological changes initiated by WSA were hepatotoxicity and toxic effects exerted upon the endocrinological system, specifically on the adrenals. The resulting data from this study are discussed below and are considered to be indicative of significant toxicity.

\section{Liver toxicity}

Data collected from this study that indicate the liver toxicity parameters measured are summarized in Tables 2-1, 2-2 and 2-3 (Tables 2-1, 2-2 and 2-3).

1) Oral administration of WSA

An increase in the liver weight, hypertrophy of hepatocytes and fatty changes in the hepatocytes were detected and documented by the completion of the treatment period. These alterations were very slight for the $30 \mathrm{mg} / \mathrm{kg}$ and slight for the $90 \mathrm{mg} / \mathrm{kg}$ group. Paralleling these morphological changes, a decrease in the total cholesterol level and an increase in the triglyceride level in the serum were observed on Days 13 and 27. These parameters are indicators of hepatotoxicity and were more pronounced in the male than in the female monkeys. There was no detectable hepatotoxicity in the $10 \mathrm{mg} / \mathrm{kg} \mathrm{WSA}$ group (Table 2-1).

\section{2) Intravenous continuous infusion of WSA}

An increase in the liver weight, hypertrophy of the hepatocytes and/or eosinophilic changes in the perilobular hepatocyte were detected and documented by the completion of the treatment period. These alterations were appraised as very slight for the female and slight for the male monkeys from the $60 \mathrm{mg} / \mathrm{kg}$ group. Again, paralleling these morphological changes, a decrease in the total cholesterol level and an increase in the triglyceride level in the serum were observed on Day 13. For the $30 \mathrm{mg} / \mathrm{kg}$ group, a slight increase in the liver weight and an increase in the serum triglyceride level were recorded in the male monkeys, and the fatty changes in the centrilobular hepatocytes were also observed as very slight in the female monkeys. Overall, the indicators of hepatotoxicity were more severe for the male than for the female monkeys. There was no detectable drug-related hepatotoxicity observed in the $10 \mathrm{mg} / \mathrm{kg}$ group (Table 2-2).

3) Oral administration of the active metabolite

An increase in the liver weight, hypertrophy of the hepatocytes and/or fatty changes in the hepatocytes were detected and documented by the completion of the treatment period. These alterations were observed to be very slight for the $90 \mathrm{mg} / \mathrm{kg}$ group. Paralleling these morphological changes, a decrease in the total cholesterol level and an increase of triglyceride level in the serum were recorded on Day 13. Furthermore, a decrease in the total cholesterol level was observed in the male monkey from the $30 \mathrm{mg} / \mathrm{kg}$ group. These indicators of hepatotoxicity were more severe for the male than for the female monkeys. There was no detectable hepatotoxicity in the $10 \mathrm{mg} / \mathrm{kg}$ group (Table 2-3).

\section{Endocrinological toxicities}

Data collected from this study indicates endocrinological toxicity, observed primarily in the adrenals as summarized in Tables 3-1, 3-2 and 3-3 (Tables 3-1, 3-2 and 3-3).

1) Oral administration of WSA

An increase in the adrenal weight and a thickening of the zona fasciculata with an increase of lipid droplets were observed in both male and female monkeys from the $90 \mathrm{mg} / \mathrm{kg}$ group. An increase in the adrenal weight was measured and recorded in male from the $30 \mathrm{mg} / \mathrm{kg}$ group. There was no detectable endocrinological toxicity observed in the $10 \mathrm{mg} / \mathrm{kg}$ group (Table 3-1).

\section{2) Intravenous continuous infusion of WSA}

An increase in the adrenal weight was measured and recorded in both the male and female monkeys from the $60 \mathrm{mg} / \mathrm{kg}$ group. Furthermore, there was a very slight increase of lipid droplets in the cortical cells in the zona fasciculata in the male monkey from the 60 $\mathrm{mg} / \mathrm{kg}$ group. In the $30 \mathrm{mg} / \mathrm{kg}$ WSA group, a slight increase in the adrenal weight and an increase in the lipid droplets was very slightly observed in a female monkey. There was no detectable endocrinological toxicity in the $10 \mathrm{mg} / \mathrm{kg}$ group (Table 3-2).

3) Oral administration of the active metabolite

An increase in the adrenal weight was measured and recorded in both male and female monkey from the $90 \mathrm{mg} / \mathrm{kg}$ group. There was a very slight increase of lipid droplets in the cortical cells in the zona fasciculata in the male monkey from the $90 \mathrm{mg} / \mathrm{kg}$ group and in the female monkey from the $30 \mathrm{mg} / \mathrm{kg}$ group. There was no detectable endocrinological toxicity found in the $10 \mathrm{mg} / \mathrm{kg}$ group (Table 3-3).

\section{Other toxicities}

1) Other changes in the monkeys that expired during the 4-week oral toxicity study

In the monkeys that expired in the $90 \mathrm{mg} / \mathrm{kg}$ group, an opportunistic bacterial infection that led to a 
K. KOBAYASHI et al.

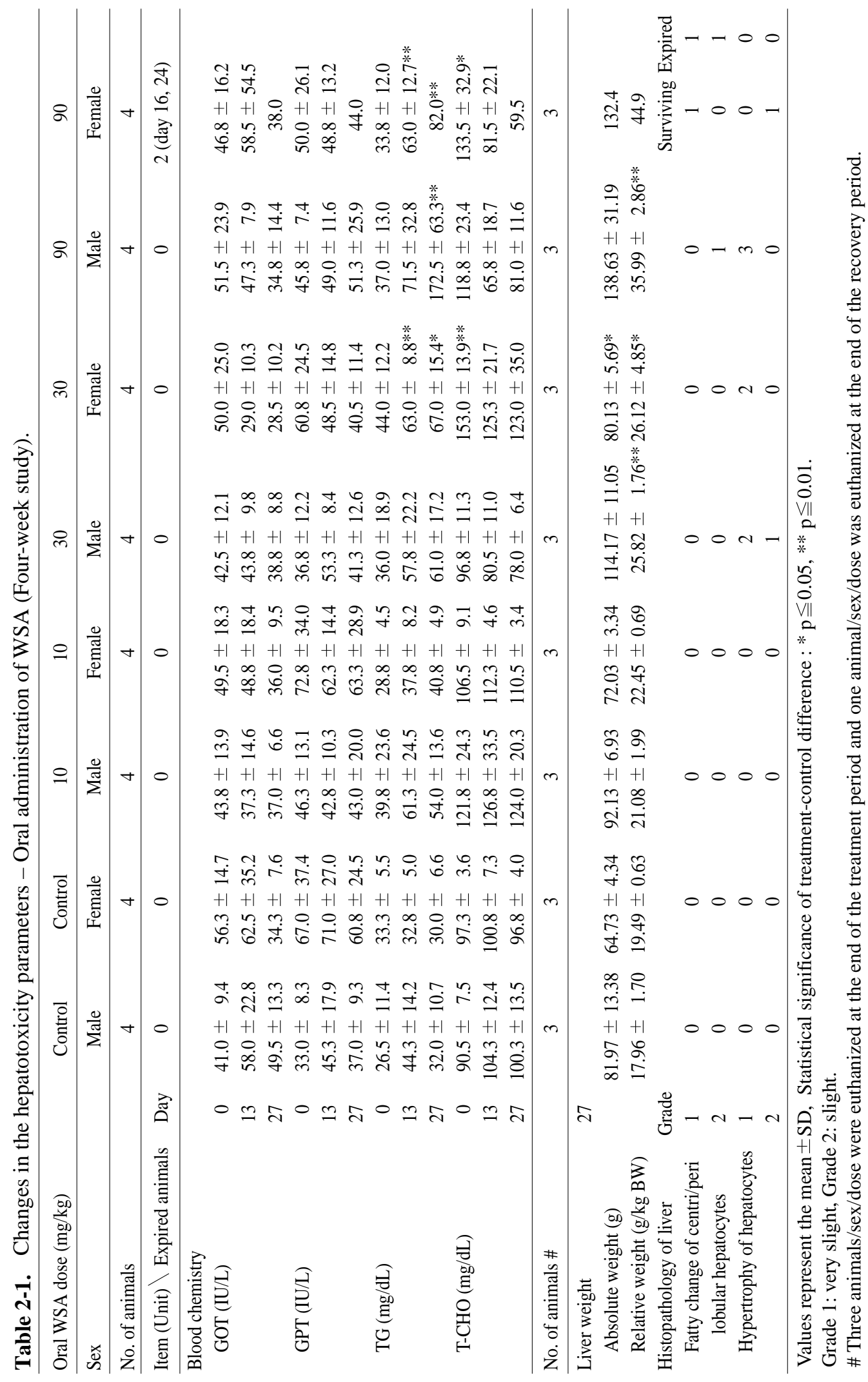


Comparative toxicological assessment of WSA in cynomolgus monkeys.

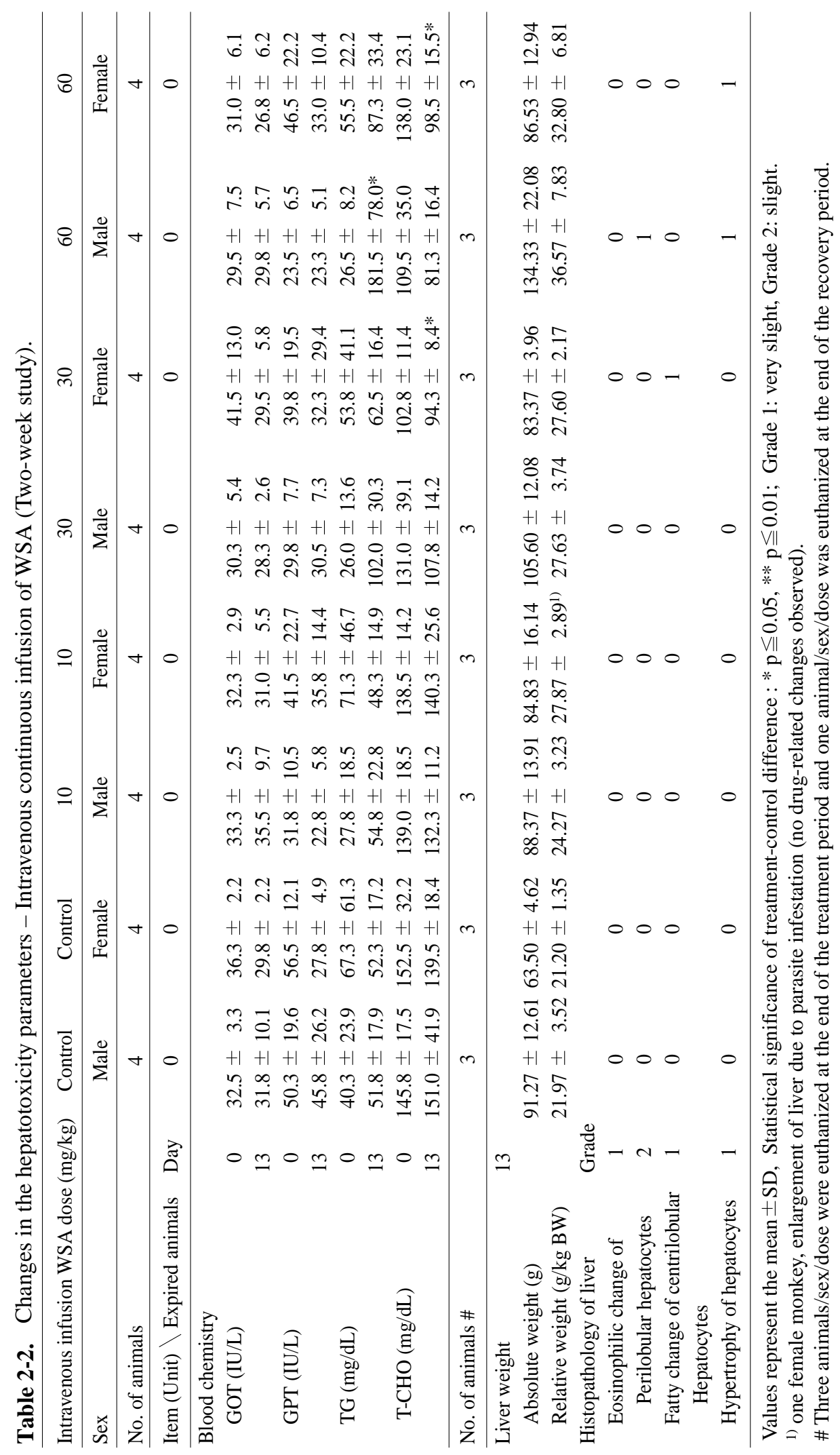


K. KOBAYASHI et al.

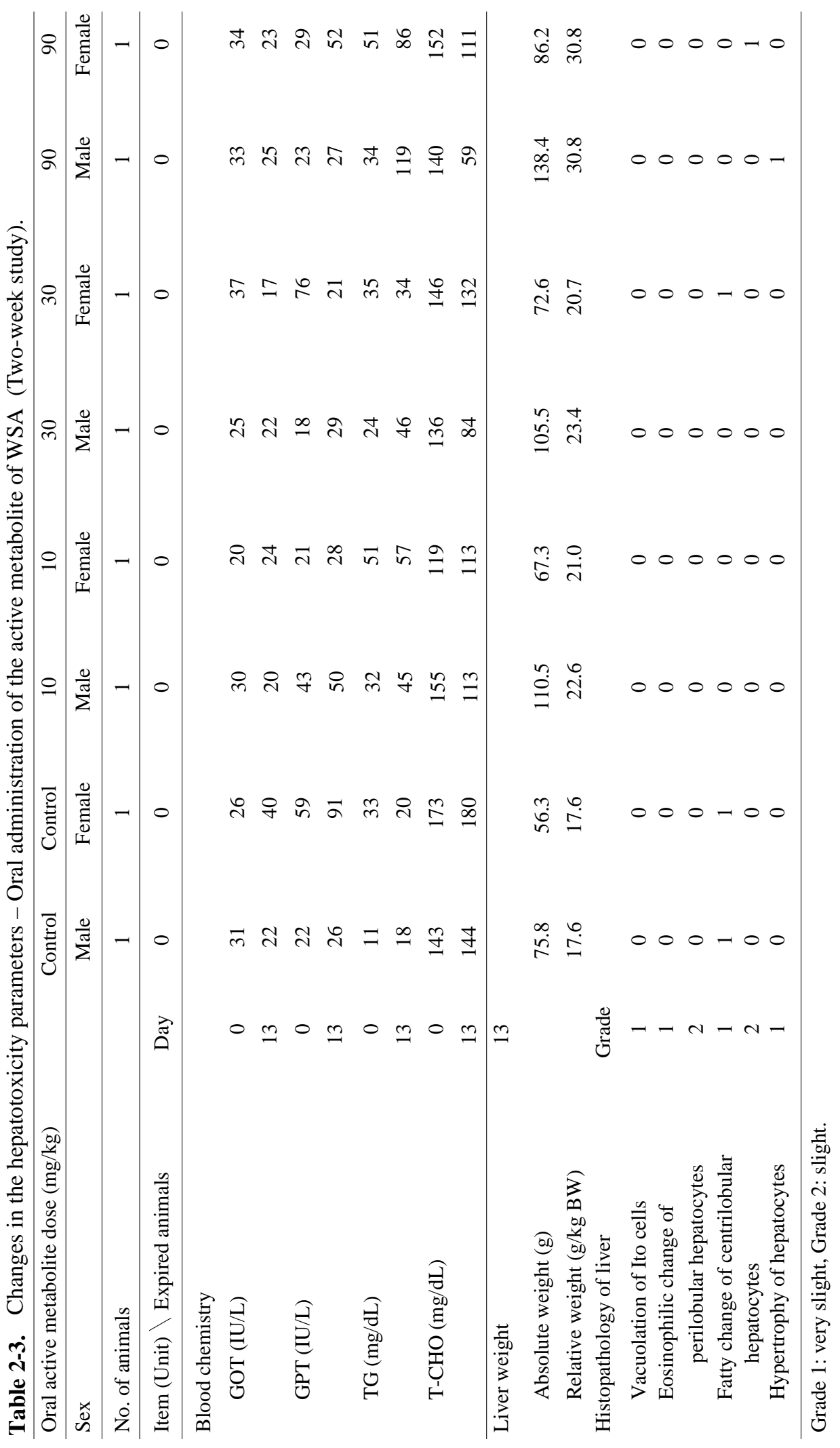


Comparative toxicological assessment of WSA in cynomolgus monkeys.

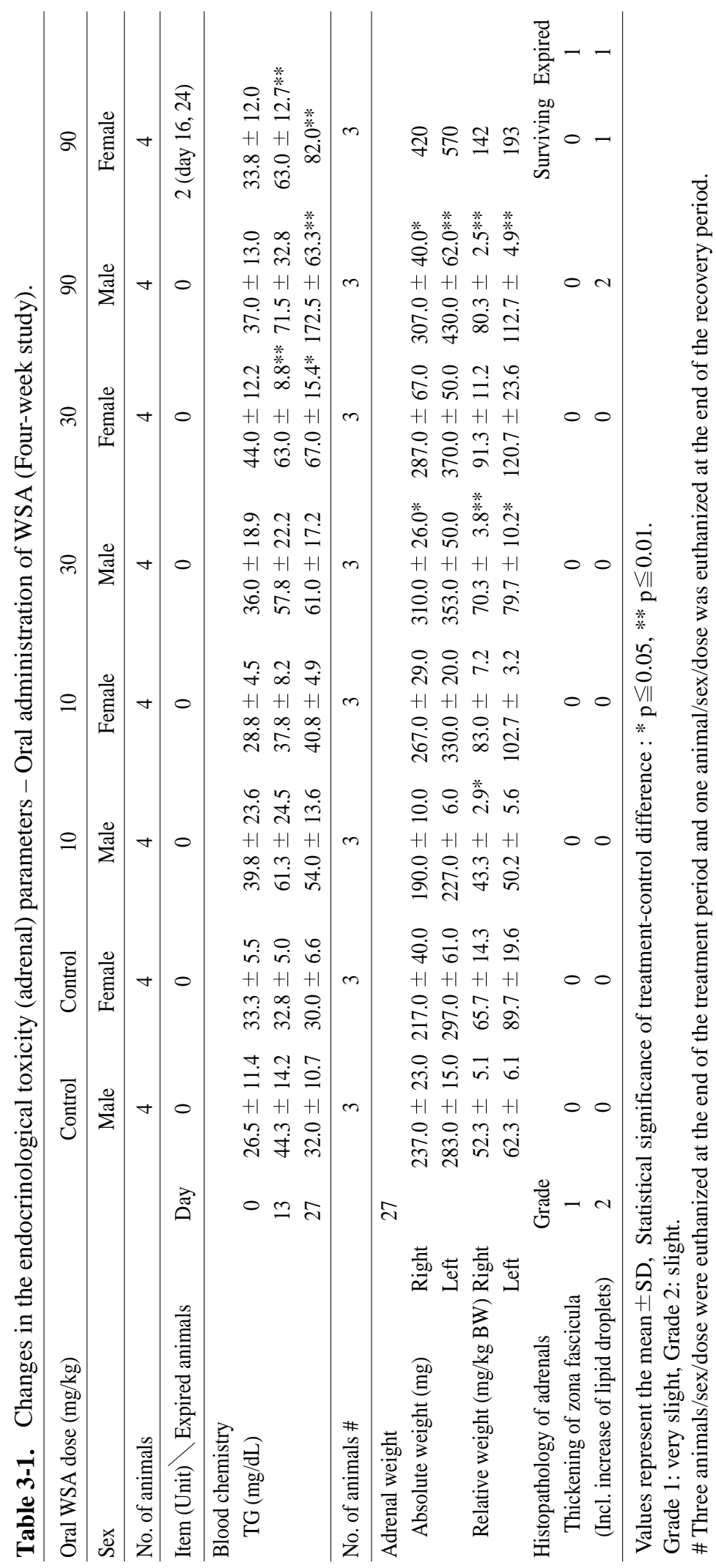


K. KOBAYASHI $e t a l$.

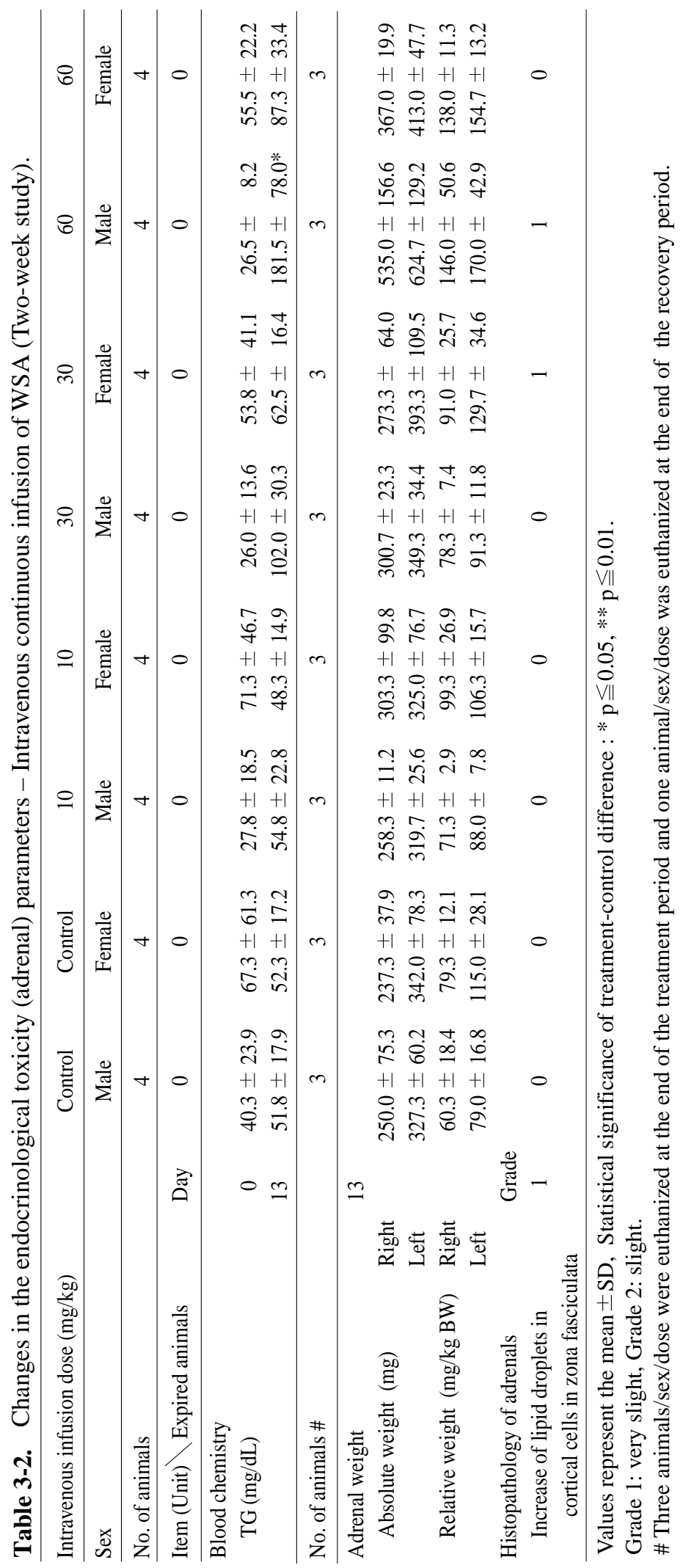


Comparative toxicological assessment of WSA in cynomolgus monkeys.

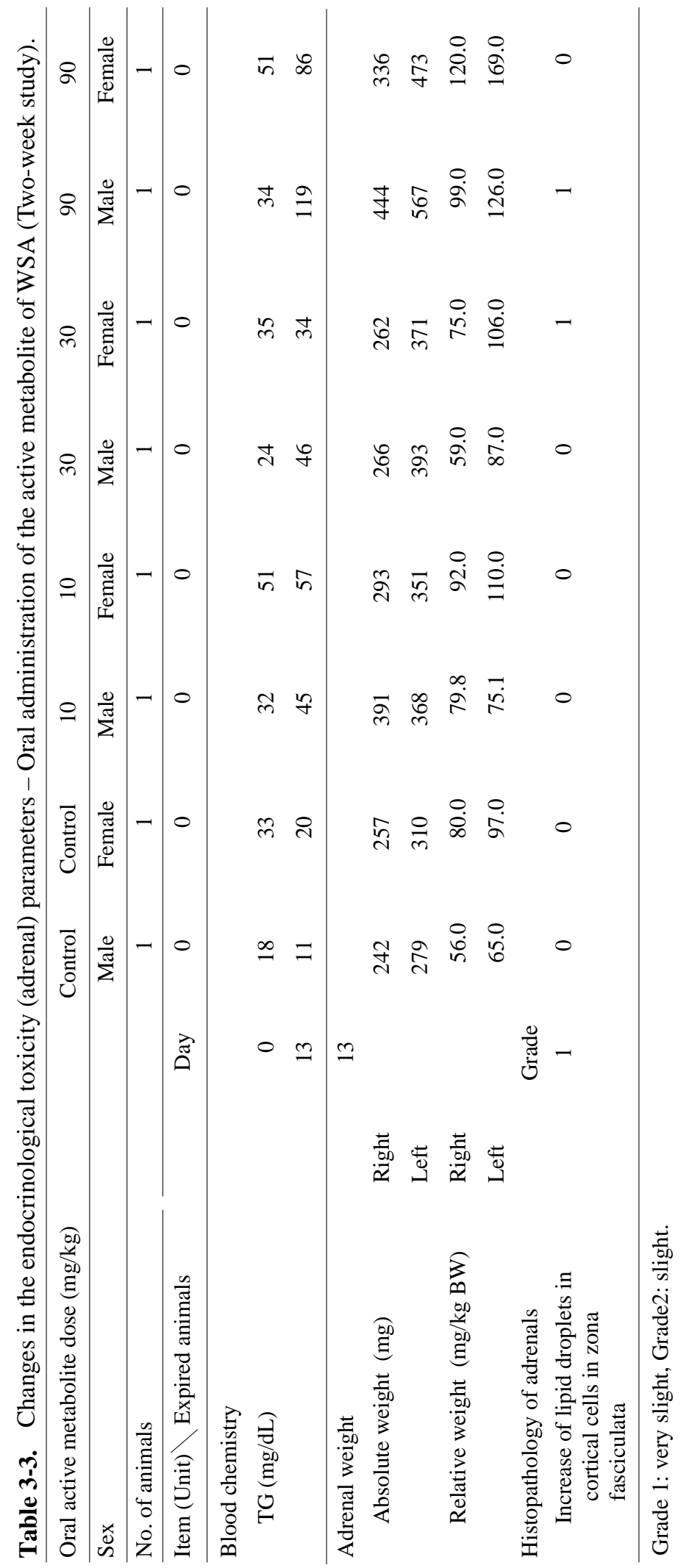


deterioration in these animals' body condition was observed and considered to be a secondary change such as the increases in the serum values for BUN and creatinine, renal tubule degeneration, atrophy of lymphoid tissues and so on.

\section{Toxicokinetics}

The plasma concentrations of the WSA, the active metabolite and the pro-moiety were closely examined throughout the treatment period. The results obtained are shown in Table 4.

After the completion of the intravenous continuous infusion of WSA, systemic exposure to WSA was relatively low and brief due to the rapid conversion of WSA to the active metabolite. The metabolic pathway of WSA in the plasma is shown in Fig. 2.

As shown in Table 4, the systemic exposure of the monkeys to the active metabolite was high, during the repeated infusion and oral administration period. The AUC of the active metabolite increased in nearly a dose-proportional pattern. These results suggest that the WSA was efficiently absorbed and converted at all concentrations tested. Systemic exposure to the active metabolite was high (AUC in i.v. (Male/Female): WSA: $3.04 / 2.62,9.34 / 7.76,10.1 / 17.9 \mu \mathrm{g} . \mathrm{hr} / \mathrm{ml}$; active metabolite: 31.0/34.1, 100.0/85.0, 190.0/230.0 $\mu \mathrm{g} . \mathrm{hr} /$ $\mathrm{ml}$ at 10,30 and $60 \mathrm{mg} / \mathrm{kg}$, respectively) and the AUC of the active metabolite increased in more than a doseproportional manner in the high dosage group. No substantial accumulation of WSA, the active metabolite or the pro-moiety was observed during the repeated administration period. The levels of the $\mathrm{C}_{\max }$ and the AUC of the active metabolite exhibited dose-dependent values during the administration period for the 10 $\mathrm{mg} / \mathrm{kg}$ and $30 \mathrm{mg} / \mathrm{kg}$ groups. However, in the groups of monkeys administered the highest WSA concentrations, the $\mathrm{C}_{\max }$ and the AUC of the active metabolite were increased. This was attributable to a decreasing metabolism due to the deteriorating physical condition of these monkeys (Days 13 and 27). In particular, in the 4-week oral administration study, the monkeys that expired from the $90 \mathrm{mg} / \mathrm{kg}$ group had a delayed $\mathrm{T}_{\max }$ (surviving monkeys: 2 - 7hr, dying monkeys: 7 - $24 \mathrm{hr}$ ) and higher AUC values (surviving monkeys: 30 - 66.6 $\mu \mathrm{g} . \mathrm{hr} / \mathrm{ml}$, dying monkeys: 128 - $189 \mu \mathrm{g} . \mathrm{hr} / \mathrm{ml}$ ) than the surviving female monkeys.

In the 2-week oral administration study of the active metabolite in monkeys, the plasma concentrations of the active metabolite was very comparable to values from the oral administration of WSA study (Table 4, Fig. 2).

\section{DISCUSSION}

Toxicity studies of a new water-soluble azole (WSA) were performed in cynomolgus monkeys given WSA by oral and intravenous administration (infusion). The purpose of these studies was to estimate and evaluate toxicities when the WSA was administered both orally and intravenously, and to compare the toxicity of WSA to the active metabolite exposure.

In the repeated administration studies over 2week or 4-week periods, the toxicological profiles of WSA were observed primarily in the liver and adrenals, the common and expected situation for azole compounds (Nishikawa et al., 1984; Buchi et al., 1986; Van Cauteren et al., 1987, 1991; Tachibana et al., 1987; Davey, 1990).
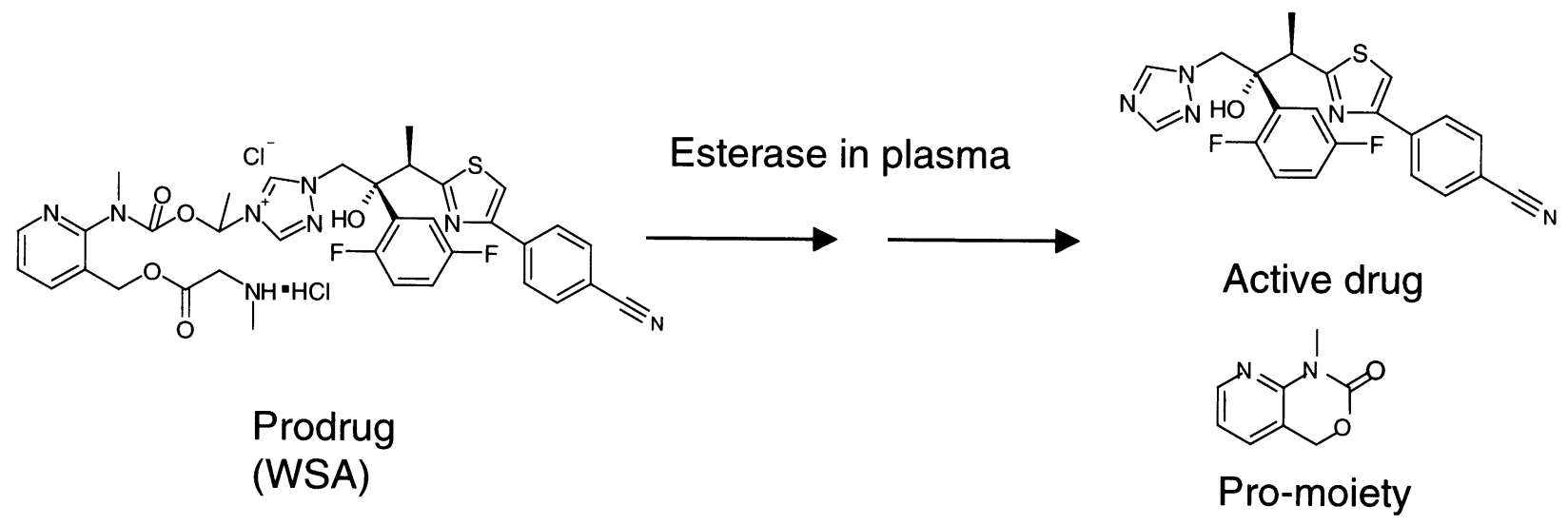

Fig. 2. Metabolic pathway of WSA in the plasma. 
Comparative toxicological assessment of WSA in cynomolgus monkeys.

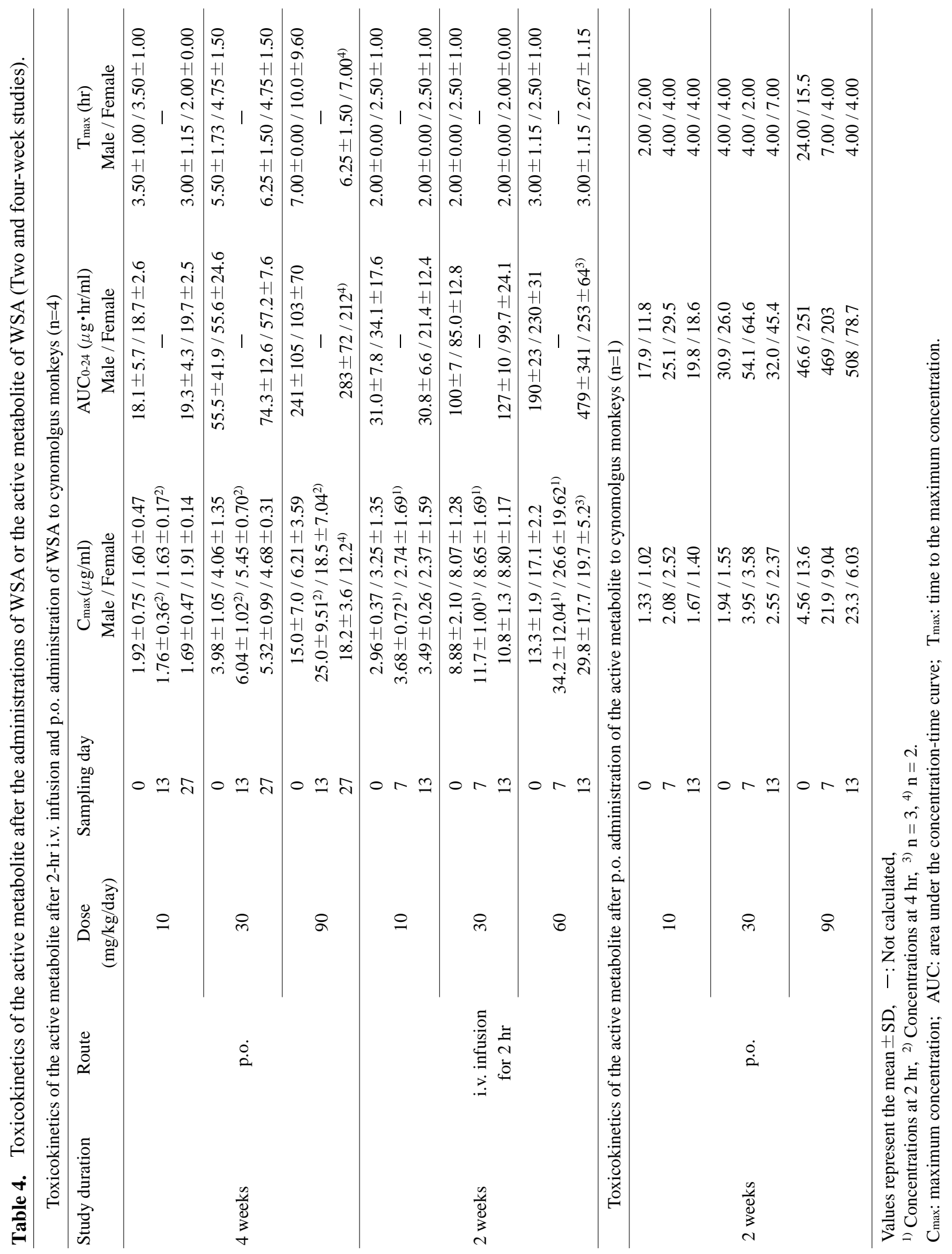


A summary of the main toxicities detected in this study is shown in Table 5. In the 4-week WSA oral administration study, the lethal dose was determined to be $90 \mathrm{mg} / \mathrm{kg}$. At the $90 \mathrm{mg} / \mathrm{kg}$ level, two female monkeys expired on Days 16 and 25. In the 2-week intravenous continuous infusion study, no monkeys from any of the treatment groups died. However, the higher WSA dosage groups from both of these studies (oral and intravenous) exhibited marked behavioral changes in their general conditions, such as a decreases in their food consumption and body weight, vomiting, a decrease in spontaneous motor activity and loose stool/ diarrhea.

For the plasma concentration of the active metabolite at 10 and $30 \mathrm{mg} / \mathrm{kg}$ levels, the $\mathrm{C}_{\max }$ and AUC had nearly constant values that demonstrated dose-proportionality over all administration periods in all of our studies, including the direct administration of the active metabolite. However, with higher doses, the systemic exposure to the active metabolite increased, resulting in a pattern beyond the dose-proportionality for these indices. Specifically, the $\mathrm{C}_{\max }$ and AUC of the active metabolite increased after Day 13. The higher plasma concentrations observed in the late phases of the high-dose regimen could be a result of or be enhanced by the deteriorating physical condition of the monkeys and the decrease in animal metabolism.

Liver toxicities were observed in the $90 \mathrm{mg} / \mathrm{kg}$ group in the 4-week oral WSA administration study and in the $60 \mathrm{mg} / \mathrm{kg}$ group in the 2-week intravenous continuous infusion study. In the 2 -week oral administration study of the active metabolite, the $90 \mathrm{mg} / \mathrm{kg}$ group demonstrated the same level of toxicity. Furthermore, the plasma concentration of the active metabolite, which displayed toxic effects, was almost the same value in both of these studies.

The following changes were detected and considered to be indicative of liver toxicity. For blood chemistries, an increase in the TG and a decrease in the TCHO level from Day 14 were observed, and an increase in the liver weight measurement and histopathological changes was observed in the liver (hypertrophy and fatty and/or eosinophilic changes in the hepatocytes) at the end of the administration period.

Endocrinological toxicities were detected in the $90 \mathrm{mg} / \mathrm{kg}$ from the 4-week oral WSA administration study and in the $60 \mathrm{mg} / \mathrm{kg}$ group from the 2-week intravenous continuous infusion study. The endocrinological toxicities observed in this study were an increase in the adrenal weight measurements and histopathological change in the adrenals such as thickening of the zona fasciculata and increased lipid droplets. These toxicity indicators were observed very slightly in the $30 \mathrm{mg} / \mathrm{kg}$ group at the end of the administration period. Increased lipid droplets were detected in the 2-week administration study. However, in the 4-week administration study, the adrenals displayed both a thickening of the zona fasciculata and increased lipid droplets. The presence of this additional toxicity indicator, specifically, the thickening of the zona fasciculata, may be dependent on the length of the exposure period.

In the oral administration study, the endocrinological toxicity for male and female monkeys was of comparable severity, but for intravenous continuous infusion study, the males treated with $60 \mathrm{mg} / \mathrm{kg}$ exhibited more severe toxicity than the female monkeys. In these studies, the values for $\mathrm{C}_{\max }$ and AUC were very similar for both male and female monkeys, except for the $\mathrm{C}_{\max }$ and $\mathrm{AUC}$ values for the $60 \mathrm{mg} / \mathrm{kg}$ group from the 2-week infusion study. At the $60 \mathrm{mg} / \mathrm{kg}$ level, the $\mathrm{C}_{\max }$ and AUC values were higher for the males than for the female monkeys. The $\mathrm{C}_{\max }$ and AUC values on Day 13 were almost identical for the females treated with $60 \mathrm{mg} / \mathrm{kg}$ via intravenous administration as were found in the male and female monkeys treated with 90 $\mathrm{mg} / \mathrm{kg}$ of WSA via oral administration. In addition, the observed changes in the biochemical and morphological parameters were nearly identical for both the 60 and $90 \mathrm{mg} / \mathrm{kg}$ groups. The $\mathrm{C}_{\max }$ and AUC values for the intravenous infusion group were approximately 2 times higher than the levels from the oral administration at the low and middle dosage levels. This suggested that the toxicities may be correlated with the $\mathrm{C}_{\max }$ and AUC values of the active metabolite.

After intravenous continuous infusion of WSA, the systemic exposure to WSA was relatively low due to its rapid conversion to the active metabolite, and the AUC increased as the concentration of the administered dose increased. This indicates that the WSA was converted rapidly to the active metabolite after its administration.

In the intravenous continuous infusion study, WSA was converted rapidly into the active metabolite. The oral bioavailability of the active metabolite was good, approximately $87 \%$, in the monkeys, and the $\mathrm{T}_{1 / 2}$ of the active metabolite was $12.8 \mathrm{hr}$ (Nakano et al., 2000).

Overall, in these repeated administration WSA studies, given orally and intravenously, the toxicity was observed to primarily affect the liver and adrenals. The results are consistent with earlier research on other azole compounds, such fluconazole and itraconazole 
Comparative toxicological assessment of WSA in cynomolgus monkeys.

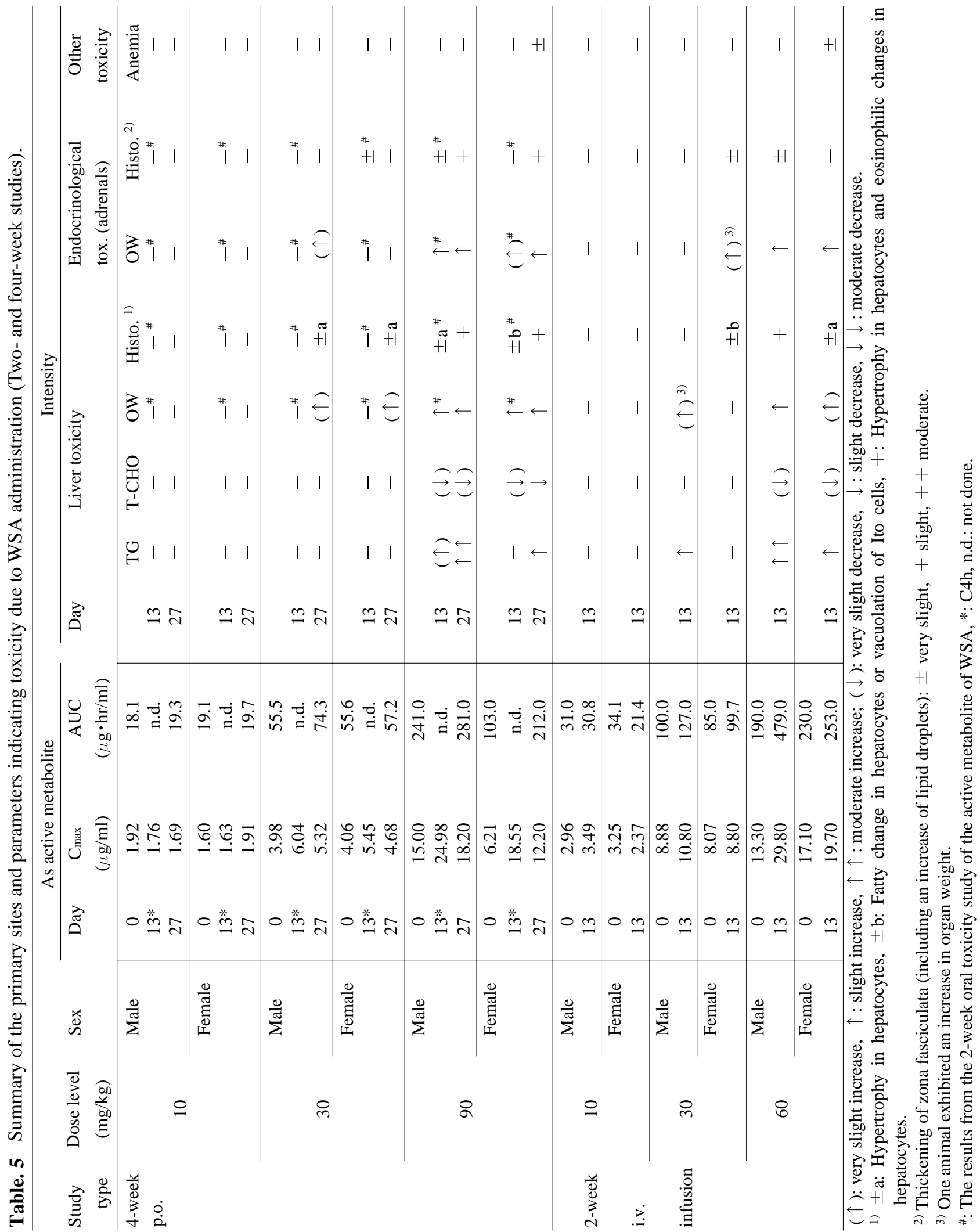




\section{K. KOBAYASHI $e t$ al.}

(Bodey, 1992; Davey, 1990; Tachibana et al., 1987; Van Cauteren et al., 1987). The toxicological intensity of WSA can be described as nearly comparable to these older azole compounds, based upon the therapeutic ratio.

No specific toxicity, other than liver and adrenal, was detected, which has been a common result in studies of other azole compounds.

In addition, by maintaining the concentration of the active metabolite of WSA at effective and nontoxic levels using intravenous continuous infusion, the safety range would be expected to be wider than for intravenous bolus administration alone. Furthermore, clinical application using intravenous continuous infusion would be an effective first intensive treatment, followed by oral administration.

\section{ACKNOWLEDGMENT}

The authors would like to thank Mr. A. Kawashima, Mr. A. Inomata, Mr. K. Nakano, Dr. S. Ichihara and other coworkers of the department of Preclinical Science at Nippon Roche Research Center for their contribution with these studies.

\section{REFERENCES}

Bodey, G.P. (1992): Azole antifungal agents. Clin. Infect. Dis., Suppl. 1, 161-169.

Buchi, K.N., Gray, P.D. and Tolman, K.G. (1986): Ketoconazole hepatotoxicity; An in vitro model. Biochem. Pharmacol., 35, 2845-2847.

Davey, P.G. (1990): New antiviral and antifungal drugs. Br. Med. J., 300, 793-798.

Lehmann, E.L. (1975): Rank tests for comparing two treatments. In Nonparametrics (Lehmann, E.L. and D'Abrera H.J.M., eds.), pp.1-54, McGrawHill and Holden-day Inc., San Francisco.

Mendenball, V., Cornell, S. and Scalaro, M.A. (2000): Surgical preparation and infusion of the large primate. In Handbook of Pre-clinical Continuous Intravenous Infusion (Healing, G. and Smith, D., eds.), pp. 163-180, Taylor \& Francis, New York.
Nakano, K., Kobayashi, K., Kawashima, A., Ichihara, S. and Horii, I. (2000): A single dose toxicity study of Ro 09-8557/001 in monkeys (oral, i.v. and infusion). Internal report, Nippon Roche.

Niki, Y., Nakajima, M. and Matsushima, T. (1999): Present problems and future trend of antifungals for deep-seated mycosis - Azole antifungal agents -. Jpn. J. Med. Mycol., 40, 163-168.

Nishikawa, T., Hara, T., Miyazaki, E. and Ohguro, T. (1984): Safety study of KW-1414 (I) Acute toxicity in mice and rats, and oral sub-acute and chronic toxicity study in rats. The Clinical Report, 18, 1401-1425.

Tachibana, M., Noguchi, Y. and Monro, A. M. (1987): Toxicology of Fluconazole in experimental animals. In Recent Trends in the Discovery, Development and Evaluation of Antifungal Agents (Fromtling, R. A., ed.), pp.93-101, J.R. Prous Science Publishers, S.A., Barcelona.

Van Cauteren, H., Coussement, W., Vandenberghe, J., Herin, V., Vanparys, Ph. and Marsboom, R. (1987): The toxicological properties of itraconazole. In Recent Trends in the Discovery, Development and Evaluation of Antifungal Agents (Fromtling, R. A. ed.), pp. 263-271, J. R. Prous Science Publishers, S. A., Barcelona.

Van Cauteren, H., Lampo, A., Vandenberghe, J., Vanparys, P., Coussement, W., Niemegeers, J.E.C., Megens, A., Marsboom, R. and Koyama, K. (1991): Toxicological profile of itraconazole, a new antifungal triazole. The Clinical Report, 25, 381-386.

Van Cauteren, H., Lampo, A., Vandenberghe, J., Vanparys, Ph, Coussement, W., Coster, De R. and Marsboom, R. (1989): Toxicological profile and safety evaluation of antifungal azole derivatives. Mycoses, 32 (Suppl. 1), 60-66.

Walker, M.D. (2000): Multidose infusion toxicity studies in the large primate. In Handbook of Pre-clinical Continuous Intravenous Infusion (Healing, G. and Smith, D., eds.), pp. 181-209, Taylor \& Francis, New York.

Yamaguchi, H. (2000): New trend of deep-seated mycosis therapy. Jpn. J. Med. Mycol., 41, 221228. 